\title{
Relationship of Fat Patterning to Coronary Artery Disease Risk in Obese Adolescents
}

\author{
M. DANIEL BECQUE, KOMEI HATTORI, VICTOR L. KATCH, AND \\ ALBERT P. ROCCHINI \\ Behnke Laboratory for Body Composition Research, Department of \\ Kinesiology, Division of Physical Education, and Department of \\ Pediatric Cardiology, School of Medicine, University of Michigan, \\ Ann Arbor, Michigan 48109-2214
}

KEY WORDS Fat patterning, Obesity, Adolescents, Skinfolds, Percent fat, Risk factors, CHD, CAD

\begin{abstract}
Fatness and fat patterning of 27 male and 33 female obese adolescents were identified by principal-components analysis of five skinfolds (triceps, subscapular, iliac, abdominal, and thigh). Correlations were computed between the component scores, based on the eigen vectors, and anthropometric ancl physiological variables. Overall fatness, component I, was highly correlated with all anthropometric and body composition variables. Also, component I significantly correlated with fasting insulin and $\mathrm{VO}_{2} \max$ for both sexes and with basal metabolism and HDL-cholesterol for females and males, respectively. Extremity fat patterning, component II, was poorly correlated with all the anthropometric and physiological variables except diastolic blood pressure for the females. Upper-lower body fat patterning, component III, was correlated with the fewest physiological variables.
\end{abstract}

Fatness and fat patterning have been the focus of research for the past three decades (Edwards, 1950, 1951; Reynolds, 1951; Garn, 1954, 1955; Garn and Harper, 1955; Newman, 1955; Malina, 1966; Malina et al., 1982; Watson, 1984). Recently, Mueller and Reid (1979), Ramirez and Mueller (1980), and Mueller and Wohlleb (1981) applied principal-components analysis to the determination of fat patterning.

Vague et al. (1956, 1969, 1974) and Feldman et al. (1969) found fat distribution to be a risk factor for diabetes and coronary artery disease. Kissebah et al. (1982) used the brachial to femoral adipose muscular ratio outlined by Vague et al. (1969) and demonstrated in adults that upper-body fat patterning strongly correlated with metabolic complications of obesity.

Although body composition and fat pat terning studies of children have been published (Parizkova, 1961; Forbes, 1964; Mueller and Reid, 1979; Ramirez and Mueller, 1980; Deutsch et al., 1985), no data are available on the relationship between fat patterning and various physiological vari- ables. Therefore, the present study describes the fat patterning of obese adolescents and examines the relationship of fat patterning with anthropometric and physiological variables often associated with increased cardiovascular risk.

\section{MATERIALS AND METHODS}

As part a multidimensional study of adolescent obesity, 60 obese adolescents (27 males and 33 females) were tested for body composition and anthropometric and physiological variables. For admittance to the study, all subjects met two criteria as established by the NHANES II national survey data: body mass and triceps skinfold greater than the 75th percentile for age and sex.

Skinfolds were measured with a Lange skinfold caliper at the triceps, subscapular, iliac, abdominal, and thigh skinfold sites

Received October 24, 1985; revision accepted July 9, 1986.

Komei Hattori's present address is Laboratory of Anatomy and Physical Fitness, Faculty of General Education, Ibaraki University, Mito, Ibaraki, Japan 310. 
(Behnke and Wilmore, 1974). Measurements to the nearest millimeter were made in duplicate on the right side of the body by a trained technician. The mean of both trials was used for all analyses.

Height was measured to the nearest millimeter with a standard stadiometer. Fourteen girths (neck, shoulder, chest, waist, abdominal, buttocks, thigh, knee, calf, ankle, upper arm extended, upper arm flexed, forearm, wrist) were measured to the nearest millimeter (Behnke and Wilmore, 1974). Body mass index (BMI) was computed as (Bw/ $\left.\mathrm{H} t^{2}\right) \cdot 100$. Body surface area (BSA) was calculated from height and mass with the equation of Dubois and Dubois (1916). Brachial to femoral adipose muscular ratio (B/F-AMR) was determined according to Vague et al. $(1954,1969)$ except that the upper arm girth and triceps skinfold were employed to calculate the brachial area, and the thigh girth and thigh skinfold were used to calculate the femoral area.

Resting heart rate and systolic and diastolic blood pressures were measured supine after admittance for an overnight stay in the Clinical Research Unit of University Hospital. The next morning ( $12 \mathrm{~h}$ postabsorptive), basal metabolism was measured via open circuit spirometry with a mask and meteorological balloon setup (Katch et al., 1985). Expired gases were immediately analyzed for $\mathrm{CO}_{2}$ and $\mathrm{O}_{2}$ concentration with an Instrumentation Laboratory End Tidal $\mathrm{CO}_{2}$ monitor and Beckman OM-11 $\mathrm{O}_{2}$ analyzer, respectively. Expired volume was measured with a Collins respirometer. Oxygen uptake $\left(\mathrm{VO}_{2}\right)$ and carbon dioxide production $\left(\mathrm{VCO}_{2}\right)$ were calculated according to standard procedures and expressed STPD (Consolazio et al., 1963). Kilocalories per minute ( $\mathrm{kcal} / \mathrm{min})$ were calculated from the nonprotein respiratory exchange ratio (Consolazio et al., 1963). $\mathrm{Kcal} / \mathrm{min}$ were multiplied by 24 to arrive at an estimate of $\mathrm{kcal} / 24 \mathrm{~h}$. The basal metabolic rate (BMR) was calculated by multiplying $\mathrm{kcal} / \mathrm{min}$ by 60 and dividing by the BSA to yield $\mathrm{kcal} / \mathrm{h} / \mathrm{m}^{2}$.

Following BMR measurements, and with the subject supine, blood was drawn for the determination of insulin, growth hormone, dihydroepiandrosterone sulfate (Dheas), aldosterone, blood lipids, and total cholesterol. Two hours later, after rising, dressing, and cleaning, blood was drawn for the determination of standing aldosterone. All blood analyses were performed by the clinical laboratories of University Hospital using standard techniques.

At 11 A.M., the subjects reported to the Exercise Physiology Laboratory for the determination of maximum oxygen uptake $\left(\mathrm{VO}_{2}\right.$ $\max ) . \mathrm{VO}_{2} \max$ was measured during a discontinuous bicycle ergometer stress test using open-circuit spirometry which included a Hans Rudolph Pneumotachograph connected to a Validyne pressure transducer, carrier demodulator and integrator, $\mathrm{O}_{2}$ and $\mathrm{CO}_{2}$ analyzers described above, and an electronic strip chart recorder. The cycle test started at $0 \mathrm{~W}$, and the resistance was increased by 50 W every $3 \mathrm{~min}$. After each workload the subject rested for 3-5 min. The test was terminated when the subject could no longer complete a $3 \cdot \mathrm{min}$ exercise stage. The $\mathrm{VO}_{2}$ max was defined as the highest $\mathrm{VO}_{2}$ with no increase in work output. For the purpose of this report the $\mathrm{VO}_{2}$ max is reported in liters/ $\mathrm{min}$ and $\mathrm{ml} / \mathrm{kg} / \mathrm{min}$, and the maximum work. load attained during the stress test is reported in watts.

Following the stress test, body density was determined by hydrostatic weighing at residual lung volume (Katch et al., 1985). Residual lung volume was determined with the oxygen dilution technique in the bent-forward seated position. Body density was converted to body fat percentage with Siri (1956) equation.

Principal-components analysis on the correlation matrix (Table 1) of the skinfolds was employed to examine fat patterning of the males and females separately. To maintain independence of the components, the initial results were interpreted (e.g., no rotation), as suggested by Mueller and Reid (1979). From the eigen vectors, component scores were computed for each subject. These component scores were then correlated with the other measurements. All analyses were performed with the Michigan Interactive Data Analysis System (MIDAS) (Fox and Guire, 1976).

\section{RESULTS}

Descriptive statistics are shown in Table 2. Fat percent for the males and females is $39.1 \%$ and $41.3 \%$, respectively. Mean skinfold thickness ranges from $32.1 \pm 12.1 \mathrm{~mm}$ for the male subscapular to $45.5 \pm 7.7 \mathrm{~mm}$ for the female thigh. Thus, it is evident that these adolescents are overfat and can easily be classified as obese. 
TABLE 1. Correlation matrix of five skinfolds for males and females

\begin{tabular}{lccccc}
\hline & Triceps & Subscapular & Iliac & Abdominal & Thigh \\
\hline Triceps & & 0.67 & 0.64 & 0.57 & 0.78 \\
Subscapular & 0.86 & & 0.71 & 0.74 & 0.55 \\
Iliac & 0.83 & 0.79 & & 0.73 & 0.67 \\
Abdominal & 0.77 & 0.79 & 0.96 & & 0.55 \\
Thigh & 0.78 & 0.85 & 0.82 & 0.80 & \\
\hline
\end{tabular}

Figures for females in italic type.

All correlations: $\mathrm{P}<0.01$.

Principal-components analysis yielded three components from the intercorrelation matrix of the five skinfolds. These are presented in Table 3 along with the eigen values and cumulative percent variation. Inspection of the eigen vectors reveals the first component to contain only positive loadings, whereas the remaining components contain both positive and negative loadings. The first component accounts for $85 \%$ and $71 \%$ of the total variance in skinfold thickness for males and females, respectively. This component describes a fatness or size factor corresponding to the "fatness component" of Mueller and Reid (1979) and Ramirez and Mueller (1980).
The second and third components represent the pattern of fat distribution independent of size and fatness. The female second component contrasts the triceps and thigh skinfolds with the subscapular, iliac, and abdominal skinfolds. For the males, the second component contrasts the triceps, subscapular, and thigh skinfolds with the iliac and abdominal skinfolds. Thus, the second component contrasts what may be called extremity-trunk fat patterning for both sexes and accounts for $6 \%$ and $13 \%$ of the total variance for males and females, respectively.

The third component for the males contrasts the triceps and thigh skinfolds; for the females, the triceps and subscapular skin-

TABLE 2. Descriptive characteristics (mean $\pm S D$ ) of obese adolescent males and females

\begin{tabular}{|c|c|c|c|c|}
\hline \multirow[b]{2}{*}{ Variable } & \multicolumn{2}{|c|}{$\begin{array}{c}\text { Males } \\
(n=27)\end{array}$} & \multicolumn{2}{|c|}{$\begin{array}{l}\text { Females } \\
(\mathrm{n}=33)\end{array}$} \\
\hline & Mean & SD & Mean & SD \\
\hline Age (yr) & 12.8 & 1.7 & 12.8 & 1.7 \\
\hline Mass $(\mathrm{kg})$ & 74.2 & 21.37 & 69.7 & 13.08 \\
\hline Height (cm) & 158.9 & 10.84 & 155.9 & 7.54 \\
\hline Fat mass (kg) & 30.2 & 13.91 & 29.0 & 7.58 \\
\hline Lean mass (kg) & 44.6 & 9.68 & 40.7 & 7.29 \\
\hline Fat \% & 39.1 & 6.65 & 41.3 & 5.05 \\
\hline BMI & 28.9 & 4.99 & 28.5 & 3.74 \\
\hline $\mathrm{BSA}\left(\mathrm{m}^{2}\right)$ & 1.8 & 0.29 & 1.7 & 0.19 \\
\hline Triceps skinfold (mm) & 33.1 & 7.35 & 34.1 & 7.49 \\
\hline Subscapular skinfold (mm) & 32.1 & 12.11 & 37.0 & 9.42 \\
\hline Iliac skinfold (mm) & 44.4 & 10.44 & 39.6 & 9.25 \\
\hline Abdominal skinfold (mm) & 45.0 & 10.29 & 43.7 & 9.43 \\
\hline Thigh skinfold (mm) & 43.5 & 8.19 & 45.5 & 7.68 \\
\hline Arm girth $(\mathrm{cm})$ & 31.1 & 3.82 & 30.0 & 3.24 \\
\hline Chest girth $(\mathrm{cm})$ & 97.9 & 12.50 & 93.2 & 6.69 \\
\hline Abdominal girth (cm) & 100.3 & 15.00 & 96.2 & 9.62 \\
\hline Thigh girth (cm) & 63.5 & 7.39 & 64.4 & 5.62 \\
\hline B/F-AMR & 2.0 & 0.48 & 2.2 & 0.44 \\
\hline Kcal/24 h & $157 \overline{5.1}$ & 374.00 & 1422.1 & 284.91 \\
\hline $\mathrm{BMR}\left(\mathrm{kcal} / \mathrm{m}^{2} / \mathrm{h}\right)$ & 38.4 & 6.95 & 35.1 & 5.73 \\
\hline Resting heart rate (bpm) & 85.2 & 13.66 & 82.1 & 12.15 \\
\hline Resting systolic bp (mm Hg) & 123.7 & 17.80 & 124.0 & 11.48 \\
\hline Resting diastolic bp (mm Hg) & 72.8 & 15.84 & 75.1 & 12.94 \\
\hline $\mathrm{VO}_{2} \max (\mathrm{ml} / \mathrm{kg} / \mathrm{min})$ & 31.8 & 7.76 & 29.4 & 6.51 \\
\hline Maximum workload (watts) & 163.2 & 38.81 & 152.1 & 33.95 \\
\hline Fasting insulin $(\mu \mathrm{U} / \mathrm{ml})$ & 23.4 & 15.68 & 22.8 & 9.32 \\
\hline HDL-cholesterol (mg/dl) & 34.0 & 9.43 & 32.2 & 7.87 \\
\hline
\end{tabular}


TABLE 3. Eigen vectors from principal-components analysis of five skinfolds for males and females

\begin{tabular}{|c|c|c|c|c|c|c|}
\hline & \multicolumn{3}{|c|}{ Males } & \multicolumn{3}{|c|}{ Females } \\
\hline & 1 & 2 & 3 & 1 & 2 & 3 \\
\hline Triceps & 0.439 & 0.275 & -0.773 & 0.440 & -0.544 & -0.393 \\
\hline Subscapular & 0.443 & 0.519 & 0.114 & 0.448 & 0.373 & -0.599 \\
\hline Iliac & 0.460 & -0.498 & -0.074 & 0.460 & 0.221 & 0.634 \\
\hline Abdominal & 0.453 & -0.562 & 0.119 & 0.443 & 0.474 & 0.051 \\
\hline Thigh & 0.442 & 0.301 & 0.609 & 0.445 & -0.540 & 0.286 \\
\hline Eigenvalue & 4.271 & 0.315 & 0.232 & 3.566 & 0.658 & 0.339 \\
\hline $\begin{array}{l}\text { Cumulative } \\
\text { percentage } \\
\text { of variance }\end{array}$ & 85.42 & 91.72 & 96.36 & 71.32 & 84.47 & 91.26 \\
\hline
\end{tabular}

folds are contrasted with the iliac and thigh skinfolds. Thus, for both sexes the third component represents and upper-lower body fat patterning contrast and accounts for $5 \%$ and $7 \%$ of the total variance for males and females, respectively. The loadings of the other sites are small and nonsignificant.

For each subject for each component a component score was computed based on the eigen vectors. This component score can be expressed as a linear combination of the skinfolds-i.e., $\mathrm{Z}_{1}$ (male) $=0.439 \mathrm{x}_{1}{ }^{\prime}+0.443$ $\mathrm{x}_{2}{ }^{\prime}+0.460 \mathrm{x}_{3}{ }^{\prime}+0.453 \mathrm{x}_{4}{ }^{\prime}+0.442 \mathrm{x}_{5}{ }^{\prime}$, where $\mathrm{x}_{1}{ }^{\prime}=\left(\mathrm{x}_{\mathrm{i}}-\mathrm{x}_{\mathrm{i}}\right) / \mathrm{sd}_{\mathrm{i}}$. Simplified equations for the calculation of component scores are presented in Table 4.

The results of the correlation analysis between the component scores and the other dependent measures are shown in Table 5. Only those correlations that are statistically significant are presented.

As expected, overall body fatness as represented by component I is highly correlated $(\mathrm{P}<0.01)$ with several anthropometric and physiological variables (Table 5). For the males, component $I$ is positively correlated with resting heart rate $(r=0.45)$ and fasting insulin ( $r=0.55$ ). On the other hand, com- ponent $\mathrm{I}$ is negatively correlated with $\mathrm{VO}_{2}$ $\max (r=-0.75)$ and HDL-cholesterol $(r=$ $-0.40)$. For the females, kcal $/ 24 \mathrm{~h}(r=0.43)$ and fasting insulin levels $(r=-0.45)$ are positively correlated, while $\mathrm{VO}_{2}$ max is negatively correlated with component I ( $r=$ -0.54 ).

Male extremity-trunk fat patterning, component II, is not significantly correlated with any of the body composition or physiological variables. For the females, the arm $(r=$ $-0.45)$ and thigh $(r=-0.36)$ girths are negatively correlated with component II, but the fat\% $(r=-0.31)$ and fat mass $(r=-0.28)$ correlations approach significance. Thus for females, extremity-type fat patterning appears to be associated with increased body fatness.

Upper-lower body fat patterning, component III, for the males is negatively correlated with B/F-AMR $(r=-0.89)$ and maximum exercise workload $(r=-0.42)$. For females, B/F-AMR $(r=-0.42)$ is negatively correlated and HDL-cholesterol $(r=0.37)$ is positively correlated with component III.

Other correlations with the fat patterning components, though nonsignificant, are also of interest. The adrenal hormone aldoster-

TABLE 4. Equations for the calculation of first, second, and third component scores

\begin{tabular}{lc}
\hline Equations & \pm 0.5 \\
\hline Males & $\mathrm{SD}$ \\
$\mathrm{Z}_{1}=0.060 \mathrm{TR}+0.037 \mathrm{SC}+0.044 \mathrm{IL}+0.044 \mathrm{AB}+0.054 \mathrm{TH}-9.435$ & 1.03 \\
$\mathrm{Z}_{2}=0.037 \mathrm{TR}+0.043 \mathrm{SC}-0.048 \mathrm{IL}-0.055 \mathrm{AB}+0.037 \mathrm{TH}+0.363$ & 0.28 \\
$\mathrm{Z}_{3}=-0.105 \mathrm{TR}+0.009 \mathrm{SC}-0.007 \mathrm{IL}+0.012 \mathrm{AB}+0.074 \mathrm{TH}-0.261$ & 0.24 \\
Females & \\
$\mathrm{Z}_{1}=0.059 \mathrm{TR}+0.048 \mathrm{SC}+0.050 \mathrm{IL}+0.047 \mathrm{AB}+0.058 \mathrm{TH}-10.416$ & 0.94 \\
$\mathrm{Z}_{2}=-0.073 \mathrm{TR}+0.040 \mathrm{SC}+0.024 \mathrm{IL}+0.050 \mathrm{AB}-0.070 \mathrm{TH}+1.068$ & 0.41 \\
$\mathrm{Z}_{3}=-0.053 \mathrm{TR}-0.064 \mathrm{SC}+0.069 \mathrm{IL}+0.005 \mathrm{AB}+0.037 \mathrm{TH}-0.503$ & 0.29 \\
\hline
\end{tabular}

Abbreviations: TR, triceps; SC, subscapular; IL, iliac; $\mathrm{AB}$, abdominal; $\mathrm{TH}$, thigh skinfold. 
TABLE 5. Correlation coefficients between component scores and selected anthropometric, body composition, and physiological variables

\begin{tabular}{|c|c|c|c|c|c|c|}
\hline & \multicolumn{3}{|c|}{ Males } & \multicolumn{3}{|c|}{ Females } \\
\hline & 1 & 2 & 3 & 1 & 2 & 3 \\
\hline Mass & $0.73^{* *}$ & & & $0.56 * *$ & & \\
\hline Height & $0.36^{*}$ & & & & & \\
\hline Fat mass & $0.79^{* *}$ & & & $0.63^{* *}$ & & \\
\hline Lean mass & $0.51^{* *}$ & & & $0.38^{*}$ & & \\
\hline Fat $\%$ & $0.80^{* *}$ & & & $0.44^{*}$ & & \\
\hline BMI & $0.88^{* * *}$ & & & $0.67 * *$ & & \\
\hline $\mathrm{BSA}$ & $0.64 * *$ & & & $0.49^{* *}$ & & \\
\hline Triceps skinfold & $0.91 * *$ & & $-0.37 *$ & $0.83^{* *}$ & $-0.44^{*}$ & \\
\hline Subscapular skinfold & $0.91 * *$ & & & $0.85^{* *}$ & & $-0.35^{*}$ \\
\hline Iliac skinfold & $0.95 * *$ & & & $0.87^{* *}$ & & $0.37 *$ \\
\hline Abdominal skinfold & $0.94^{* *}$ & & & $0.84^{* *}$ & $0.38^{*}$ & \\
\hline Thigh skinfold & $0.91 * *$ & & & $0.84^{* *}$ & $-0.44^{*}$ & \\
\hline Arm girth & $0.79^{* *}$ & & & $0.54^{* *}$ & $-0.45^{* *}$ & \\
\hline Chest girth & $0.80^{* * *}$ & & & $0.66^{* *}$ & & \\
\hline Abdominal girth & $0.85^{* *}$ & & & $0.63^{* *}$ & & \\
\hline Thigh girth & $0.74 * *$ & & & $0.45^{* *}$ & $-0.36^{*}$ & \\
\hline B/F-AMR & & & $-0.89 * *$ & $0.43^{*}$ & & $-0.42^{*}$ \\
\hline $\mathrm{Kcal} / 24 \mathrm{~h}$ & & & & $0.43^{*}$ & $-0.43^{*}$ & \\
\hline BMR & & & & & $-0.49^{*}$ & \\
\hline Resting heart rate & $0.45^{*}$ & & & & & \\
\hline Resting diastolic $\mathrm{hp}$ & & & & & $-0.55^{* *}$ & \\
\hline $\mathrm{VO}_{2} \max$ & $-0.75^{* *}$ & & & $-0.54 * *$ & & \\
\hline Maximum workload & & & $-0.42^{*}$ & & & \\
\hline Fasting insulin & $0.55^{* *}$ & & & $0.45^{*}$ & & \\
\hline HDL-cholesterol & $-0.40^{*}$ & & & & & $0.37^{*}$ \\
\hline
\end{tabular}

$* \mathrm{P}<0.05 ; * * \mathrm{P}<0.01$

one, which is involved with the regulation of sodium reabsorption by the kidneys and may have profound effects on blood pressure, correlates $r=0.46$ and $r=0.37$ with component I for males and females, respectively.

The absence of substantial correlations between the component scores and such variables as resting systolic blood pressure, Dheas, triglycerides, and total cholesterol is surprising in light of their often-cited association with increased cardiovascular risk. This lack of consistency in the correlations between fat patterning and cardiovascular risk variables is important. Therefore, it does not seem justified to conclude that a particular fat pattern is suggestive of increased risk in obese adolescents, as it may be for adults.

Table 6 presents the correlations between various risk variables and the raw skinfold values. The waist-to-hip girth ratio $(\mathrm{W} / \mathrm{H}$ ratio) is included as a further indicator of trunk fat patterning. These correlations generally mirror the correlations with component $\mathrm{I}$. This is not surprising, since both are measures of body fatness. However, there are several exceptions.

Three of the five male skinfolds are significantly correlated with diastolic blood pres- sure (subscapular, $r=0.37$; iliac, $r=0.37$; abdominal, $r=0.38$ ). Although these correlations are significant, they are quite small and account for less than $15 \%$ of the common variance between the variables $\left(r^{2} \cdot 100\right)$. Systolic blood pressure of both males and females is poorly related with the raw skinfolds.

While the skinfolds and sum of skinfolds are moderately correlated with insulin, none are correlated with total cholesterol or triglycerides. The correlations with HDL-cholesterol are also moderate and unremarkable. These relationships are similar to the correlations with the component scores.

Also of interest are the correlations with the $\mathrm{W} / \mathrm{H}$ girth ratio. This often-used indicator of centripetal fat deposition and increased CAD risk (Björntorp, 1985) does not correlate any better than the raw skinfolds or component scores.

\section{DISCUSSION}

Principal-components analysis of five skinfolds has identified three fat pattern components for obese male and female adolescents: overall fatness (component I), extremitytrunk fat patterning (component II), and up- 
TABLE 6. Correlation coefficients between raw skinfolds, sum of skinfolds, waist-to-hip girth ratio, and selected risk variables

\begin{tabular}{lllllllr}
\hline & $\mathrm{Tr}$ & $\mathrm{Sc}$ & $\mathrm{n}$ & $\mathrm{Ab}$ & $\mathrm{Th}$ & $\Sigma$ skf & W/H \\
\hline Systolic BP & 0.19 & 0.25 & 0.10 & 0.16 & 0.13 & 0.13 & 0.06 \\
& 0.14 & 0.06 & 0.33 & 0.17 & 0.22 & 0.17 & $-0.48^{*}$ \\
Diastolic BP & 0.30 & $0.37^{*}$ & $0.37^{*}$ & $0.38^{*}$ & 0.34 & 0.35 & 0.33 \\
& $0.41^{*}$ & 0.09 & 0.24 & -0.07 & $0.38^{*}$ & 0.20 & -0.30 \\
$\mathrm{VO}_{2}$ max & -0.06 & -0.19 & -0.15 & -0.10 & -0.26 & -0.13 & $-0.40^{*}$ \\
& 0.09 & 0.12 & 0.06 & -0.07 & -0.02 & -0.02 & $-0.39^{*}$ \\
Insulin & $0.71^{*}$ & $0.65^{*}$ & $0.53^{*}$ & $0.50^{*}$ & $0.38^{*}$ & $0.55^{*}$ & 0.15 \\
& $0.56^{*}$ & $0.59^{*}$ & $0.56^{*}$ & $0.38^{*}$ & 0.28 & $0.45^{*}$ & 0.30 \\
Cholesterol & 0.22 & 0.20 & 0.06 & 0.10 & 0.15 & 0.01 & 0.04 \\
& 0.00 & 0.00 & 0.06 & 0.17 & -0.04 & 0.11 & 0.07 \\
Triglycerides & 0.13 & 0.26 & 0.07 & -0.05 & 0.09 & -0.01 & 0.24 \\
& 0.25 & 0.02 & 0.09 & 0.07 & 0.14 & 0.13 & 0.23 \\
HDL- & -0.28 & $-0.51^{*}$ & -0.34 & -0.35 & -0.39 & $-0.42^{*}$ & -0.10 \\
cholesterol & -0.22 & $-0.48^{*}$ & -0.19 & -0.33 & 0.04 & -0.20 & -0.16 \\
\hline
\end{tabular}

Abbreviations: Tr, triceps skinfold; Sc, subscapular skinfold; Il, iliac skinfold; Ab, abdominal skinfold; Th, thigh skinfold; $\Sigma$ skf, sum of five skinfolds; $\mathrm{W} / \mathrm{H}=$ waist-to-hip girth ratio. Correlations for females are in italics. $* \mathrm{P}<0.05$.

per-lower body fat patterning (component III). Components II and III are very similar to those identified by Mueller and Reid (1979) for Colombian adults and children. In our data, components I and III are similar for males and females. Component II differs between males and females. For the males, the extremity component includes the subscapular skinfold, whereas the subscapular skinfold is a trunk fat pattern site for the females. This transposition of the subscapular skinfold between the sexes makes interpretation difficult. It is possible that variability in age, maturation, or sex has caused this condition. To adjust for age, a regression between age and the component scores was done, and partial correlations with age held constant were done between fat pattern components and the various risk measures. These analyses revealed no significant age effect. Thus, one must conclude that sex or maturity, independent of chronological age, is the primary cause of between-sex differences in fat patterning.

The present data reveal that for the obese adolescent male, trunk fat is located in the abdominal and iliac region, but for the obese adolescent female trunk fat is located at all three sites on the torso: subscapular, iliac, and abdominal.

Increased lower-body fat for the males occurs particularly at the thigh, whereas for females lower-body fat occurs at both the thigh and iliac sites. Likewise, increased up. per-body fat for the males occurs at the tri- ceps site and for females at the triceps and subscapular sites. Overall, obese adolescent females seem to have fat distributed over a greater number of skinfold sites for each component than the males. This agrees with the observations of Vague et al. (1959) that female body fat is more evenly distributed over the body surface.

Component I, overall fatness, is strongly correlated with numerous physiological and anthropometric variables for both males and females. As can be expected, overall body fatness is associated with increases in all body composition and anthropometric variables as well as with increased fasting insulin levels and basal metabolism (kcal/24 h). Furthermore, increased fatness for males is associated with increased resting heart rate and decreased $\mathrm{VO}_{2} \max$ and HDL-cholesterol. As in the males, increased fatness in obese adolescent females is associated with a lower $\mathrm{VO}_{2}$ max and higher fasting insulin levels.

Component II, trunk fat patterning, is for the females associated with lower total body fat. Furthermore, as trunk fat patterning increases, so does resting diastolic blood pressure, a recognized cardiovascular risk factor.

Upper-lower body fat patterning is correlated in both males and females with the brachial to femoral adipose muscular ratio (B/F-AMR). Vague et al. (1956, 1969, 1974) have demonstrated that B/F-AMR is related to diabetes, gout, atherosclerosis, and uric calculous disease in adults. In contrast, our 
data with obese male and female adolescents show that upper-lower body fat patterning is at best only moderately associated with similar disease markers.

The equations in Table 4 can be used to estimate the fat patterning of an obese male or female adolescent. The resultants are component scores that can be compared to the present distribution to ascertain the overall fatness, extremity-trunk fat patterning, and upper-lower body fat patterning of the subject. For each component $\pm 0.5 \mathrm{SD}$ is included. This division was chosen to divide the distribution roughly into thirds, but any criterion can be derived for a component by using the square root of the eigenvalue as $\pm 1 \mathrm{SD}$ unit. Therefore, scores for males from equations 2 and 3 greater than $0.5 \mathrm{SD}$ units indicate extremity fat patterning and lowerbody fat patterning, respectively. Likewise, scores for females from equations 2 and 3 greater than $0.5 \mathrm{SD}$ units indicate trunk fat patterning and lower-body fat patterning, respectively.

In summary, in addition to an overall fatness component, two components of fat patterning were derived for male and female obese adolescents: extremity-trunk and upper-lower body. The similarity of these components between males and females is interesting and suggests a common biological fat patterning for obese adolescents. These components were shown to be only moderately correlated with many anthropometric, body composition, and metabolic variables.

\section{ACKNOWLEDGMENTS}

Supported in part by grant NIH-AM/HD 30989.

\section{LITERATURE CITED}

Behnke, AR, and Wilmore, JH (1974) Evaluation and Regulation of Body Build and Body Composition. Englewood Cliffs: Prentice-Hall.

Björntorp, P (1985) Regional patterns of fat distribution. Ann. Intern. Med. 103:994-995.

Consolazio, CF, Johnson, RE, and Pecora, LJ (1963) Physiological Measurements of Metabolic Functions in Man. New York: McGraw-Hill.

Deutsch, MI, Mueller, WH, and Malina, RM (1985) Androgyny in fat patterning is associated with obesity in adolescents and young adults. Ann. Hum. Biol. 12: $275-286$.

Dubois, D, and Dubois, EF (1916) A formula to estimate the approximate surface area of the body if height and weight be known. Arch, Intern, Med. 17:863-871.

Edwards, DAW (1950) Observations on the distribution of subcutaneous fat. Clin. Scin. 9:259-270.

Edwards, DAW (1951) Differences in the distribution of subcutaneous fat with sex and maturity. Clin. Sci.
$10: 305-315$.

Feldman, R, Sender, AV, and Siegelaub, AB (1969) Differences in diabetic and nondiabetic fat distribution pattern by skinfold measurements. Diabetes 18: $478-486$.

Forbes, GB (1964) Lean body mass and fat in obese children. Pediatrics 34:308-314.

Fox, DJ, and Guire, KE (1976) Documentation for Midas. Ann Arbor: University of Michigan Press.

Garn, SM (1954) Fat patterning and fat intercorrelations in the adult male. Hum. Biol. 26:59-69.

Garn, SM (1955) Relative fat patterning: An individual characteristic. Hum. Biol. 27:76-89.

Garn, SM, and Harper, RV (1955) Fat accumulation and weight gain in the adult male. Hum. Biol. 27:39-49.

Katch, V, Rocchini, P, Becque, D, Marks, C, and Moorehead, $C$ (1985) Basal metabolism of obese adolescents: Age, gender and body composition effects. Int. J. Obes. 9:69-76.

Kissebah, AH, Vydelingum, N, Murray, R, Evans, DJ, Hartz, AJ, Kalkhoff, RK, and Adams, PW (1982) Relation of body fat distribution to metabolic complications of obesity. J. Clin. Endocrinol. Metab. 54:254-260.

Malina, RM (1966) Patterns of development in skinfolds of Negro and white Philadelphia children. Hum. Biol. 38:89-105

Malina, RM, Mueller, WH, Bouchard, C, Shoup, RF, and Lariviere, G (1982) Fatness and fat patterning among athletes at the Montreal olympic games, 1976. Med. Sci. Sports Exer. 14:445-452.

Mueller, WH, and Reid, RM (1979) A multivariate analysis of fatness and relative fat patterning. Am. J. Phys. Anthropol. 50:199-208.

Mueller, WH, and Wohlleb, JC (1981) Anatomical distribution of subcutaneous fat and its description by multivariate method: How valid are principal components? Am. J. Phys. Anthropol. 54:25-34.

Newman, RW (1955) Skinfold changes with increasing obesity in young American males. Hum. Biol. 27: 53-64.

Parizkova, J (1961) Age trends in fatness in normal and obese children. J. Appl. Physiol. 16:173-174.

Ramirez, ME, and Mueller, WH (1980) The development of obesity and fat patterning in Tokelau children. Hum. Biol. 54:675-687.

Reynolds, EL (1951) The distribution of subcutaneous fat in childhood and adolescence. Monogr. Soc. Res. Child Dev., Vol. 15, Series 5.

Siri, WE (1956) Gross composition of the body. In JH Lawrence and CA Tobias (eds): Advances in Biological and Medical Physics, Vol. IV. New York: Academic Press.

Vague, $\mathbf{J}$ (1956) The degree of masculine differentiation of obesities: A factor determining predisposition to diabetes, atherosclerosis, gout and uric calculous disease. Am. J. Clin. Nutr. 4:20-34

Vague, J, Boyer J, Jubelin, J, Nicolino, C, and Pinto, C (1969) Adipomuscular ratio in human subjects. In $\mathbf{J}$ Vague and R Denton (eds): Physiopathology of Adipose Tissue. Amsterdam: Excerpta Medica, pp 360-386

Vague, J, Rubin, P, Jubelin, J, Lam-Van, G, Aubert, F, Wassermann, AM, and Fondarai, J (1974) Regulation of the adipose mass: Histometric and anthropometric aspects. In $J$ Vague and $J$ Boyer (eds): Regulation of the Adipose Tissue Mass. Amsterdam: Excerpta Medica, pp. 296-310.

Watson, AMS (1984) Distribution of subcutaneous fat in sportsmen: Relationship to anaerobic power-output. J. Sports Med. 24:195-204. 